IZA DP No. 8957

Does Professional Development of Preschool Teachers Improve Child Socio-Emotional Outcomes?

Bente Jensen

Peter Jensen

Astrid Würtz Rasmussen

March 2015 


\title{
Does Professional Development of Preschool Teachers Improve Child Socio-Emotional Outcomes?
}

\author{
Bente Jensen \\ Aarhus University \\ Peter Jensen \\ Aarhus University and IZA \\ Astrid Würtz Rasmussen \\ Aarhus University \\ Discussion Paper No. 8957 \\ March 2015 \\ IZA \\ P.O. Box 7240 \\ 53072 Bonn \\ Germany \\ Phone: +49-228-3894-0 \\ Fax: +49-228-3894-180 \\ E-mail: iza@iza.org
}

\begin{abstract}
Any opinions expressed here are those of the author(s) and not those of IZA. Research published in this series may include views on policy, but the institute itself takes no institutional policy positions. The IZA research network is committed to the IZA Guiding Principles of Research Integrity.

The Institute for the Study of Labor (IZA) in Bonn is a local and virtual international research center and a place of communication between science, politics and business. IZA is an independent nonprofit organization supported by Deutsche Post Foundation. The center is associated with the University of Bonn and offers a stimulating research environment through its international network, workshops and conferences, data service, project support, research visits and doctoral program. IZA engages in (i) original and internationally competitive research in all fields of labor economics, (ii) development of policy concepts, and (iii) dissemination of research results and concepts to the interested public.
\end{abstract}

IZA Discussion Papers often represent preliminary work and are circulated to encourage discussion. Citation of such a paper should account for its provisional character. A revised version may be available directly from the author. 


\section{ABSTRACT}

\section{Does Professional Development of Preschool Teachers Improve Child Socio-Emotional Outcomes?}

From 2011 to 2013 a randomized controlled trial has been run in Danish preschools to obtain evidence on improvements of early childhood education by providing training to the preschool teachers. The purpose of the intervention is to improve child socio-emotional outcomes (measured by SDQ), especially for socially disadvantaged children. The intervention preschools received extra training of the preschool teachers, whereas control preschools did not receive any training. The results show improvements in several subscales of the SDQ scale. However, the intervention proves less beneficial for socially disadvantaged children, in particular as a consequence of unfavorable preschool characteristics.

JEL Classification: $\quad$ I21, J13, J24

Keywords: preschools, childcare, child development, RCT, professional development, intervention

Corresponding author:

Peter Jensen

Department of Economics and Business

Aarhus University, School of Business and Social Sciences

Fuglesangs Allé 4

DK - 8210 Aarhus V

Denmark

E-mail: pje@econ.au.dk

\footnotetext{
* We thank the Danish Ministry of Children, Gender Equality, Integration and Social Affairs and the Centre for Strategic Research in Education (CSER) for financial support. Comments from Sven Bremberg, Frank Niklas, and Marianne Simonsen as well as participants at the EALE 2013 conference, the ESPE 2013 conference, the $8^{\text {th }}$ Nordic Summer Institute in Labor Economics, the Applied Micro Seminar at DIW Berlin, and the Brownbag Lunch Workshop at Aarhus University are highly appreciated. The usual disclaimer applies.
} 


\section{Introduction}

In recent years, it has become increasingly clear that the foundation for children's future success in life is laid very early in life (see e.g. Cunha et al., 2006) and that socio-emotional skills are as important as cognitive abilities (Heckman and Kautz, 2012). Early childhood educational interventions are likely to be an important factor in improving the life chances of individuals from socially disadvantaged families, e.g. poor families (Barnett and Masse, 2007; Schweinhart et al., 2005; Burger, 2010). According to Heckman (2008), the advantages gained from effective early interventions are best sustained when they are followed by continued high-quality learning experiences. Hence, to improve individual child development, it is very important to provide highquality childcare and early childhood education programs and to obtain more knowledge of how to design such early childhood education programs to improve school readiness, increase educational attainment, and lay the foundation for future labor market success.

Existing evidence suggests that early interventions typically improve child socio-emotional and cognitive outcomes (Heckman et al., 2010), also in the long run (Heckman, 2008; Pianta et al., 2009). However, much of this evidence on the effects of early childhood education is based on small model programs offered to disadvantaged children at few specific locations in North America and implemented as randomized controlled trials, for example the Perry Pre-School Project (Barnett and Belfield, 2006), The Carolina Abecedarian Approach (Barnett and Masse, 2007), and the Chicago Child-Parent Centers (Temple and Reynolds, 2007). Several studies have focused on longterm effects, documenting the importance of early childhood education for later life outcomes. ${ }^{1}$ There is also evidence from large-scale publicly funded interventions, such as Head Start in the US. $^{2}$ Blau and Currie (2006) conclude that the existing evidence from model programs and Head Start suggests that socially disadvantaged children benefit more from early interventions than other

\footnotetext{
${ }^{1}$ A survey of many of these studies is given by Almond and Currie (2011).

${ }^{2}$ Such evidence is typically non-experimental; see Blau and Currie (2006) for a survey.
} 
children do. Other recent studies also conclude that early childhood education programs have considerably positive short-term effects on cognitive development, and that socially disadvantaged children benefit at least as much as their more advantaged peers (Burger, 2010; Duncan and Sojourner, 2013).

Evidence on the effects of early childhood education programs is sparse for European countries (Burger, 2010). A major concern is thus whether the existing evidence applies to e.g. universal programs which provide daycare arrangements for the entire population. Two large-scale Scandinavian non-experimental studies demonstrate that a universal daycare system has beneficial long-term outcomes. Bauchmüller et al. (2014) investigate whether quality variations in early childhood education and care in Denmark have any long-term impacts on child cognitive outcomes and they find persistent positive associations from high-quality preschools ${ }^{3}$ to the end of elementary school. Havnes and Mogstad (2011) investigate mainly long-term outcomes of a large-scale expansion of subsidized childcare in Norway and they also find positive long-term impacts of attending preschools. Newly established universal childcare programs such as the Canadian program (Baker et al., 2008) may have different effects than the universal programs which have been in place for several decades. ${ }^{4}$ However, it is still an open question whether the universal scheme benefits socially disadvantaged children relatively more than their privileged peers, although some recent studies indicate that this is the case at least for formal preschooling compared to family day care (Datta Gupta and Simonsen, 2010; Duncan and Sojourner, 2013).

One specific potential way to improve the quality of early childhood education is through professional development of preschool teachers. Pianta et al. (2009) give an extensive survey of the

\footnotetext{
${ }^{3}$ High-quality preschools are defined based on higher staff-per-child ratio, more male staff, and higher share of staff with formal preschool teacher training.

${ }^{4}$ Baker et al. (2008) investigate the introduction of large-scale universal programs for children under the age of 6 in Canada and find significantly negative effects on the children's behavioral and motor-social skills.
} 
(primarily US-based) evidence on the effects of preschool teacher qualifications showing that teacher qualifications and professional development of preschool teachers are important for child development. For Denmark, Bauchmüller et al. (2014) find that a high percentage of BA-educated staff is positively associated with child development. Chetty et al. (2011) also find that teacher qualifications are positively associated with better cognitive outcomes. However, the literature on the effects of interventions based on professional development is scarce.

In this paper, we therefore provide evidence from a randomized controlled trial on the effects of such an intervention in Danish preschools, VIDA. ${ }^{5}$ The intervention is targeted at all 3-5-year-old children in universal daycare but with special focus on disadvantaged children. The intervention trains preschool teachers to work on an evidence-based platform. The objective for the teachers is to provide the individual child with learning opportunities in daycare settings in ways that match the child's skill level as well as improve the child's skills by being responsive to the child's needs and potentials, working with the individual child and peer groups (inclusion). The paper aims to answer the question: can child socio-emotional outcomes be improved for all children by providing training to the preschool teachers within the framework of the VIDA intervention?

Our contribution is to provide new empirical evidence on the effects of targeting children through professional development of preschool teachers. This evidence is from a relatively large randomized controlled trial taking place in Denmark, a country with a universal system of childcare. The specific research questions are: Does pedagogical training based on learning and knowledge sharing (the VIDA intervention) improve socio-emotional outcomes of children in preschools? If yes, does the effect vary among different groups of children (e.g. due to gender or family status) or based on differences of preschools (e.g. turnover rate of staff)?

\footnotetext{
${ }^{5}$ VIDA is a Danish acronym for Knowledge-based efforts for socially disadvantaged children in daycare.
} 
Our results show that an intervention based on professional development of preschool teachers leads to improvements in the socio-emotional skills of the children, especially as regards emotional symptoms and conduct problems. However, the intervention is not successful in producing larger improvements for socially disadvantaged children than for other children. Further investigations also show that various characteristics of the preschools may act as barriers to a successful outcome of the intervention; no improvements are generally found for children attending preschools with a high share of socially disadvantaged children or a high turnover rate among the staff.

\section{Institutional Settings of Preschools in Denmark}

In this section, we briefly present the organization of Danish preschools in the relevant period, 2011-2013. Danish parents use organized childcare on a large scale. For example, in 1998, almost $70 \%$ of 1-year-old children attended a formal childcare arrangement, and more than $90 \%$ of 3-5year-olds attended childcare. Attendance rates have continued to rise and today $97 \%$ of 3-5-yearolds attend childcare (Statistics Denmark, 2015).

The majority of Danish childcare facilities are organized and operated by the municipalities. They organize family daycare where young children (typically 0-2-year-olds) are cared for by a childminder, usually in her or his private home. Moreover, they provide center-based early childcare at nursery centers for the 0-2-year-olds, center-based preschools for children aged 3-5, and ageintegrated institutions (for the 0-5-year-olds) with a separate preschool compartment. In this study, we focus on center-based preschools and age-integrated institutions.

Children are allocated to the institutions by the local municipality. On average, half of the institutions are run directly by the municipality; the others are independent but heavily subsidized by the municipality. The latter can be considered semi-private non-profit organizations, and they 
have more autonomy and more parental influence than a municipality-run institution, but they basically function as a municipal institution as they are under municipal surveillance and supervision and also subject to the same legislation on educational quality and provisional conditions for hygiene and safety.

Parental payment is the same for institutions within a municipality, but fees vary across municipalities. The municipality decides how much of the cost parents should bear, subject to an upper cap set by national laws. Thus, parents usually pay around $20-30 \%$ of the actual cost of a preschool slot, but the price is reduced if siblings attend preschool at the same time, and there is no fee for very low-income families. For example, for the city of Aarhus, a free slot is provided to families with an income level below DKK $164,101^{6}$ (for the year 2015). For single parents (sole providers) the income level is further adjusted downwards with DKK 57,407.

\section{Theoretical Background}

This section briefly outlines the theoretical approach to child development that is relevant for our study. The VIDA intervention is based on the bioecological model of human development, which focuses on the social contexts in which children live (Bronfenbrenner and Morris, 2006).

Earlier approaches to child development, such as the classical behavioral approach (Morris, 1985) or the psychoanalytical tradition (Pine, 1985; Stern, 1985), viewed the individual child as the goal of interventions. The child's skill level or any disorder was seen as an inherent feature of the single child. As a consequence, teachers would stimulate the single child whereas the contexts, learning environments, peer groups and the daycare system were disregarded as a basis for interventions.

\footnotetext{
${ }^{6}$ This is equivalent to USD 24,456 (March 4, 2015: USD 100 DKK 671)
} 
In contrast, the bioecological approach to child development (Bronfenbrenner and Morris, 2006) views the child as an inseparable part of a wider system. According to this approach, the interactions between the teachers and the children are the primary mechanisms through which children develop. Hence, the child's context (family, daycare, school, or neighborhood) is critical for understanding the child's learning and development. This also means that potential disorders (e.g. language problems or behavioral problems) are not viewed as deficiencies of the child, but rather as discordance in the system, which should therefore be the focus of interventions.

Thus, the individual approaches to child development do not explore the dynamic complementarity between environment, context and child that needs to be included to fully understand the development of the child (Rutter, 2006; Cunha et al., 2006). This concept is further explored in the theory of life cycle skill formation. It shows that early investments in children generally make later investments more beneficial and suggests that non-cognitive skills such as the child's socioemotional skills can enhance the cognitive skills (Heckman, 2006; Cunha et al., 2006). It can be seen as an important extension to the bioecological approach and be understood on the basis of Vygotsky's theory of development within the sociocultural context (Vygotsky, 1978). In these theories it is assumed that children's development of non-cognitive (and cognitive) skills takes place through interactions with adults, peers, and the learning context. These theories therefore explain the influence of complex relationships between the social systems a child is part of such as the family, the preschool, and society, and naturally connect the development of outcomes over time.

The intervention studied in this paper is rooted in the bioecological approach, i.e. it does not only focus on the individual child but it instead focusses on the environment surrounding the child, in particular the preschool. This is done through professional development of the preschool teachers, and thereby the intervention aims at improving the quality of preschools by training the preschool 
teachers instead of targeting the children directly. In order for this approach to succeed, the training and later implementation in the preschools must build on responsive and supportive interactions between teacher and child. Previous research suggests that professional development interventions are a potentially effective method to improve the quality of teacher-child interactions in preschools (Mashburn et al., 2008).

\section{The VIDA Intervention}

The VIDA intervention focuses on professional development of preschools teachers to improve children's socio-emotional development. The purpose of the professional development is to qualify the preschool teachers to work on an evidence-based platform, where the objective is to provide the children with learning and development opportunities. Thus, the effects of the intervention on the children are indirect, since there is no direct targeting of the children.

The principal and one teacher from each participating preschool are offered a training program consisting of a series of educational sessions and workshops. The training program runs over a twoyear period with a total of 17 full days of training: 7 full-day educational sessions the first year (scheduled every second week over a four-month period), 7 full-day educational sessions the second year (again scheduled every second week over a four-month period) and 3 full-day practice-based sessions in the second year. In addition, the principals are each year offered a two-day course and a workshop on facilitating the organizational learning processes in the preschools (see more details on this below). This setup ensures that the participants receive support and training in relation to the implementation of their new knowledge into practice in the daily work at the preschool, which is known to strengthen the effect of the intervention (Cameron, 2012; Pianta et al., 2009; Hamre et al., 2012). 
The full intervention consists of three elements: knowledge, reflection, and activities. These three elements alternate during the two-year period of the intervention. The training program provides the new knowledge which is then the basis for reflection about practices. This reflection is supposed to lead to development of new activities that should be implemented in the preschools to improve the quality of the learning environment. These activities are developed locally by preschool teachers in order to meet the needs of the individual child and the specific social issues in the particular group of children. $^{7}$

The training program emphasizes that preschool teachers should develop and implement activities in line with the theoretical background as formulated by three perspectives: 1) the view on children is based on a resource perspective - as opposed to a deficiency perspective, 2) children are viewed as active learners - not passive recipients in their learning and development process, and 3) changes are made to the whole system - as opposed to individual learning strategies where one teacher services one child. ${ }^{8}$ In addition, the training intends to increase the preschool teachers' awareness of the impact of their approach on children's development process and competences. ${ }^{9}$

\footnotetext{
${ }^{7}$ Engaging preschool teachers in developing activities and practices at a local level ensures that challenges within the specific preschool are targeted, as e.g. improving efforts for socially disadvantaged children. Preschools in areas with many socially disadvantaged children do not get more resources from the intervention than other preschools. However, it is possible that such preschools generally are subsidized more from the municipality than other preschools. ${ }^{8}$ All activities take place in inclusive learning environments and the expected main drivers of children's learning are 1) adult-initiated learning activities with a range of selected themes based on the national curriculum, e.g. social and emotional (personal) development, language, physical development, mathematics, creative arts, and approaches to learning, 2) child-initiated learning activities exploring the same range of selected themes based on the national curriculum, 3) supporting activities that train children's language and motor skills, 4) stimulation of children's learning and wellbeing through active involvement, 5) stimulation of children's curiosity and concentration through educational games, and 6) recognition of child progress by encouraging the child to explore new aspects of his/her personality in the peer group and to embark on new activities independently.

${ }^{9}$ Inspired by the theory of Bronfenbrenner (1979), it was expected that an intervention that further improved the relationship between the family and the preschool would boost the effect of the
} 
The design of the intervention is based on research on professional development using a perspective of innovation in the public sector (Sundbo, 2003; Jensen et al., 2007) as well as on research on practice-based innovation and organizational learning (Ellström, 2010; Brown and Duguid, 1991). As described above, only the principal and one teacher from each preschool participate in the training program. Hence, the intervention relies heavily on the principle of organizational learning (Gheradi, 2011), i.e. a process where some employees acquire new knowledge and use this knowledge to change work-related practices that are then systematically adopted and practiced by all teachers in the preschool. An important tool for the organizational learning process is the use of critical-reflection groups, where new activities and practices are introduced by the participants in the training program, thereby transmitting knowledge to the entire preschool.

\section{Experimental Design and Data}

The VIDA intervention was implemented using a cluster-randomized controlled trial. ${ }^{10}$ Random assignment occurred at the preschool level. The participating preschools (and control preschools) were selected from three different municipalities in Denmark: Brøndby, Gentofte, and Randers. ${ }^{11} 12$ The randomization was done using a stratification procedure to ensure that the preschools were balanced with respect to their share of socially disadvantaged children. The stratification procedure was based on information about the parents' level of education, social welfare dependency, family

intervention. This supplementary parental intervention is known as VIDA+ in the original VIDA material. However, focus in our study is only on the VIDA Basis intervention.

${ }^{10}$ As mentioned in the previous section, two different versions of the intervention were tested in the RCT, but our study focuses only on the basis intervention.

${ }^{11}$ Brøndby and Gentofte are municipalities located in the outskirts of Copenhagen, the capital city of Denmark, while Randers is north of Aarhus, the second largest city in Denmark.

${ }^{12}$ Originally, the intervention was also implemented in a fourth municipality. However, the data on child outcomes for the control group in this municipality showed unexpected high SDQ-scores. This amounts to relatively few children in the full sample of children present in all three waves of data, and thus could not be detected in the original balancing tests. The available data did not allow us to investigate the reasons behind this further and the current study therefore only includes data from three municipalities. 
status and income. This information was obtained from Statistics Denmark (for further details, see Jensen et al., 2011). A total of 58 preschools were randomly assigned to the intervention group and the control group, resulting in each group containing 29 preschools. On average, 12 children from each preschool were observed for the full period from the baseline data collection started in March 2011 until the data collection finished two years later in March 2013.

The data for this study comes from a variety of sources. Data on child outcomes was collected by letting preschool teachers assess each child using the Strengths and Difficulties Questionnaire (SDQ), while background information on children and their parents was obtained from administrative registers at Statistics Denmark. Finally, background information on preschools was obtained from questionnaires to the administrations of the municipalities.

Child outcomes are in this study restricted to socio-emotional skills which are measured by the SDQ (Goodman, 1997). The preschool teachers assess each child using the SDQ. The SDQ measures the strengths as well as the weaknesses of the child's socio-emotional development and it contains 25 questions. It is a well-established instrument within child research and it has been utilized widely in other similar analyses, also as a pre- and post-measurement (Goodman and Goodman, 2009). We treat the five subscales of the SDQ as separate outcomes, i.e. we analyze the following five outcomes: 1) emotional symptoms, 2) conduct problems, 3) hyperactivity, 4) peer relationship problems, and 5) prosocial behavior. In addition, we analyze the total SDQ score which is obtained as the sum of the first four subscales, and the SDQ impact score which is obtained from the impact supplement of SDQ. This latter score reflects whether the preschool teacher thinks that the child has any emotional or behavioral difficulties and, if so, to what extent these difficulties result in distress and social impairment (for further details, see Goodman, 1999). The data on child outcomes was collected in three waves. Wave 1 is from March 2011 right before the start of the 
intervention period (baseline), wave 2 is from March 2012 (mid-way), and the final collection of data, wave 3, is collected in March 2013 at the end of the intervention period.

No information is available on which of the preschool teachers filled out the questionnaire for a given child, so it is not possible to account for preschool teacher fixed effects in the analysis. Thus, we cannot take into account if some preschool teachers for some reason are using the SDQ scales more (or less) generously than others. However, there is no reason to believe that this should not be at random within and between intervention and control preschools as this did not seem to be a problem in an earlier Danish study (see Jensen et al., 2013).

Each child has a unique personal identifier (due to the Danish person registry) and we use this identifier to obtain data on child characteristics from administrative registers in Statistics Denmark. Furthermore, we link the child to his/her parents and in a similar way obtain data on the home and family background. For each child, we have information on age, ethnicity, and gender. For the parents, we have information on educational level, income, and marital status.

Our analyses control for observable characteristics of preschools that might be correlated with child outcomes. This information is provided by the administrations of the municipalities for each calendar year of the study. The information includes size of each preschool (i.e. the number of children ages 3-5 served), the number of staff, the composition of the preschools' staff with respect to gender and education, and the turnover rate of the staff.

We might expect that the effect of the intervention is influenced by the turnover of preschool staff. Turnover is generally high in Denmark due to flexible hiring and firing rules, and it is therefore not surprising that turnover is also high in Danish preschools (Bauchmüller et al., 2014). However, turnover is highest among the untrained staff, and since the untrained staff are not core participants 
in the professional development provided by the intervention, this should not be a concern. The turnover rate is included in the analyses to examine this question further.

The analytic sample used in this study consists of all the children that are enrolled in intervention and control preschools for the full period of the intervention from March 2011 to March 2013. This ensures that the children in the intervention preschools have had the opportunity to experience the full effect of the intervention, which is the effect that is relevant from a policy perspective. For all of these children, we have measurements of their socio-emotional skills both before the intervention starts (baseline) and after it is completed. This sample consists of 686 children, with 396 in intervention preschools and 290 in control preschools.

In addition to this main analytic sample, we also have data on the children who either left or entered the preschools during the intervention period. These children are characterized by not having a measured outcome at all three data waves and for those in intervention preschools by not having been exposed to the full intervention. These data allow us to perform a midway analysis with an enlarged sample (see further in Section 9).

Table 1 shows the mean values and standard deviations for each SDQ measure for the main analytic sample, separately for each wave and for the intervention and control groups. There is some variation across the two groups and across outcome measures, but in general the means for the first four subscales show a clear decreasing trend from wave 1 to wave 3 , implying better outcomes for the children over time. This also leads the mean of the total SDQ score (equal to the sum of the first four subscales) to show a strong decreasing trend over time. The fifth subscale, prosocial behavior, is measured on a positive scale and its mean shows a clear increasing trend over time. Thus, on average children experience an improvement over time (i.e. during the intervention period), in the 
Table 1. Descriptive statistics for the SDQ measures

\begin{tabular}{|c|c|c|c|c|c|c|c|}
\hline \multirow[b]{2}{*}{ SDQ subscale } & \multirow[b]{2}{*}{ Obs. } & \multicolumn{2}{|c|}{ Wave 1} & \multicolumn{2}{|c|}{ Wave 2} & \multicolumn{2}{|c|}{ Wave 3} \\
\hline & & Mean & Std.dev. & Mean & Std.dev. & Mean & Std.dev. \\
\hline \multicolumn{8}{|c|}{ Emotional symptoms } \\
\hline Control & 290 & 1.51 & 1.89 & 1.53 & 2.08 & 1.53 & 1.83 \\
\hline Intervention & 396 & 1.66 & 2.01 & 1.25 & 1.65 & 1.21 & 1.80 \\
\hline \multicolumn{8}{|c|}{ Conduct problems } \\
\hline Control & 290 & 1.11 & 1.83 & 1.01 & 1.80 & 1.15 & 1.92 \\
\hline Intervention & 396 & 1.24 & 1.91 & 1.02 & 1.79 & 0.73 & 1.34 \\
\hline \multicolumn{8}{|l|}{ Hyperactivity } \\
\hline Control & 290 & 2.57 & 2.71 & 2.19 & 2.70 & 2.12 & 2.86 \\
\hline Intervention & 396 & 2.72 & 2.87 & 2.22 & 2.77 & 1.81 & 2.58 \\
\hline \multicolumn{8}{|c|}{ Peer relationship prob. } \\
\hline Control & 290 & 1.32 & 1.89 & 1.02 & 1.67 & 0.95 & 1.71 \\
\hline Intervention & 396 & 1.35 & 1.94 & 0.88 & 1.53 & 0.70 & 1.30 \\
\hline \multicolumn{8}{|c|}{ Prosocial behavior } \\
\hline Control & 290 & 6.92 & 2.67 & 7.64 & 2.62 & 8.04 & 2.23 \\
\hline Intervention & 396 & 7.22 & 2.54 & 7.82 & 2.33 & 8.59 & 1.87 \\
\hline \multicolumn{8}{|c|}{ Total SDQ score } \\
\hline Control & 290 & 6.52 & 6.03 & 5.74 & 6.22 & 5.76 & 6.53 \\
\hline Intervention & 396 & 6.98 & 6.47 & 5.37 & 5.90 & 4.45 & 5.28 \\
\hline \multicolumn{8}{|c|}{ SDQ impact score } \\
\hline Control & 284 & 0.27 & 0.73 & 0.36 & 0.75 & 0.40 & 0.85 \\
\hline Intervention & 386 & 0.27 & 0.78 & 0.28 & 0.67 & 0.21 & 0.62 \\
\hline
\end{tabular}

Note: All five subscales of SDQ are measured on a 0 to 10 scale. The total SDQ score is the sum of the first four subscales; hence, its scale is from 0 to 40. The SDQ impact score is measured on a 0 to 6 scale. 
sense that they experience fewer problems and have a better prosocial behavior. ${ }^{13}$ However, the figures in the table indicate that the children in the intervention group experience larger improvements than the children in the control group. This is examined more closely in the econometric analysis below.

Tables 2 and 3 show means and standard deviations for the background variables for the children in the main analytic sample, separately for the control and intervention groups. The child and family characteristics are presented for the year the child turns 3 and we mainly present variables that are included in the empirical analysis. $88 \%$ of the children are of Danish origin meaning that the mother, the father, or both parents are of Danish origin. Between $73 \%$ and $82 \%$ of mothers and fathers have at least 12 years of education, i.e. they have completed high school or vocational training on top of compulsory schooling. We have a computed measure of disposable family income (deflated to 2011-DKK using the consumer price index). The variation in income is quite large across families. The administrative registers offer detailed information about living arrangements, and we are thus able to control for different types of family constructions in the empirical analysis. 59-68\% of the children are living in a household with married parents (at child age 3), and 12-22\% are living with a single parent. The rest are living in cohabiting households either with both or only one of the biological parents. Hence, $78-88 \%$ of the children live with two parents, who are either married or cohabiting.

Looking at the preschool characteristics in Table 3, it is seen that the average size of the preschools is around 75 children, the staff-child ratio is around 0.20 , and more than half of the staff is educated. The average stability of the staff is close to $90 \%$, meaning that the average annual turnover rate is

\footnotetext{
${ }^{13}$ This is most likely related to the fact that children have more self-control and encounter fewer behavioral problems as they grow older, and it is as such not related to the intervention. This autonomous improvement over time or by age of the children has also been noticed in other studies using the SDQ scale (see e.g. Datta Gupta and Simonsen, 2010).
} 
around $10 \%$. In the empirical analysis, we include the stability of staff at the start of the intervention period to avoid issues of endogeneity. This initial stability of staff is highly correlated with subsequent stability of staff during the intervention period, with a year-to-year correlation of around 0.70 for the intervention group.

Table 2. Descriptive statistics for child and family characteristics, by group

\begin{tabular}{|lccccccc|}
\hline Variable* & \multicolumn{3}{c}{ Control } & \multicolumn{3}{c}{ Intervention } \\
& Obs. & Mean & Std.dev & Obs. & Mean & Std.dev \\
Boy (0/1) & 290 & 0.56 & 0.50 & 396 & 0.49 & 0.50 \\
Danish origin (0/1) & 288 & 0.88 & 0.34 & 392 & 0.88 & 0.33 \\
12 years of education, mother (0/1) & 281 & 0.79 & 0.41 & 388 & 0.82 & 0.39 \\
12 years of education, father (0/1) & 278 & 0.73 & 0.45 & 382 & 0.82 & 0.38 \\
Income less than 10\% of income & & & & & & \\
distribution (0/1) & 266 & 0.09 & 0.29 & 368 & 0.10 & 0.30 \\
Disposable family income, 2011 & & & & & & & \\
DKK & 266 & 221,000 & 97,000 & 368 & 280,000 & 229,000 \\
Parents married (0/1) & 288 & 0.59 & 0.49 & 392 & 0.68 & 0.47 \\
Living with single parent (0/1) & 288 & 0.22 & 0.41 & 392 & 0.12 & 0.32 \\
Living with two parents (0/1) & 288 & 0.78 & 0.41 & 392 & 0.88 & 0.32 \\
\hline
\end{tabular}

Note: *Background information for children is collected at the end of the year the child turns 3 .

Comparing the control and intervention groups, it is seen that the children in the control group have slightly weaker characteristics, in the sense that they are more often living with a single parent, their parents are less educated, and they attend preschools with lower staff-child ratios, lower shares of educated staff, and higher shares of socially disadvantaged children. On the other hand, they attend 
preschools with a higher stability of the staff. These differences underline the need to include these characteristics as explanatory variables in the empirical analysis.

It is also seen from the tables that not all variables are observed for all 686 children. In a few cases, we do not have information about e.g. ethnicity, parents' education or characteristics of the staff of the preschool. Such missing values occur in around 3-4\% of all observations, with a slightly higher percentage for the disposable family income. Observations with missing values are left out in the relevant estimations, thereby reducing the sample size in specific estimations.

Table 3. Descriptive statistics for preschool characteristics, by group

\begin{tabular}{|lccccccc|}
\hline Variable* & \multicolumn{3}{c}{ Control } & \multicolumn{4}{c|}{ Intervention } \\
& Obs. & Mean & Std.dev & Obs. & Mean & Std.dev \\
Size of preschool (no. of children) & 282 & 78.52 & 28.53 & 396 & 71.77 & 23.98 \\
Staff-child ratio & 277 & 0.19 & 0.04 & 396 & 0.21 & 0.04 \\
Share of educated staff & 277 & 0.56 & 0.08 & 396 & 0.60 & 0.11 \\
Stability of staff (1- annual turnover) & 277 & 0.90 & 0.14 & 396 & 0.86 & 0.14 \\
Change of principal of preschool (0/1) & 277 & 0.19 & 0.39 & 396 & 0.04 & 0.20 \\
High share of soc. disadv. children (0/1) & 290 & 0.14 & 0.35 & 396 & 0.10 & 0.31 \\
Stable preschool (low turnover rate) & & & & & & & \\
(0/1) & & & & & & & \\
\end{tabular}

Note: *Background information for preschools is collected at the start of the intervention period. 


\section{Empirical Methods}

To examine the effects of the intervention on child outcomes, we employ a value-added specification of an educational production function, i.e. we include a lagged (baseline) value of the outcome measure as explanatory variable in the econometric model (see Todd and Wolpin, 2007, for further details and discussion of this specification). The basic econometric model is specified in the following way: ${ }^{14}$

(1) $y_{i}=\boldsymbol{X}_{i} \boldsymbol{\beta}+\delta I_{i}+\gamma y_{i}^{-1}+u_{i}$

where $y_{i}$ is the outcome measure for child $i$ and $\boldsymbol{X}$ is a vector of explanatory variables that include child and family characteristics (gender and ethnicity of the child, parental education level, family income, and parents' marital status) which are included to control for individual differences that might influence the outcome measures. It also includes a set of preschool characteristics (the size of the preschool, the staff-to-child ratio, preschool teachers' educational composition, turnover rate of teachers, and change of principal) which are included to control for preschool differences that might influence child outcomes. $I_{i}$ is an indicator variable for whether the child is enrolled in an intervention preschool, which makes $\delta$ our main parameter of interest. $y_{i}^{-1}$ is the lagged (baseline) measure of child $i$ 's outcome measure. Including this measure allows us to control for unobserved characteristics that might be correlated with prior achievement (see Todd and Wolpin, 2007, for further details).

The effect of the intervention might have been estimated by the simple difference of the means of the outcome measure for the intervention and control groups (due to the random assignment), ${ }^{15}$ but we have chosen to include as many explanatory variables as possible in the specification to account

${ }^{14}$ A similar specification has been employed by Claessens et al. (2014). Raver et al. (2009) also model children's behavior problems in preschool by a specification which is essentially similar although their exposition of the model is different.

${ }^{15}$ The results of this simple estimation are shown in Table 4 in Section 7. 
for any baseline differences in the final analytic sample and to increase the statistical power (thereby following the advice of Lipsey et al., 2012). Hence, the estimated coefficient of interest in Equation 1 is $\delta$ that corresponds to the indicator variable for whether the preschool is in the intervention or control group. This coefficient gives the direct effect of the intervention net of any other characteristics at the child, family and preschool levels. In addition to the estimated intervention effects, we also calculate effect sizes by dividing the estimated coefficients by the full sample standard deviation for the dependent variable. Thereby we allow comparisons across effects and to other studies.

We estimate the model separately for each outcome measure, i.e. the five subscales of the child's SDQ index. Since the randomization occurs at the preschool level and we also include other preschool characteristics in our specification, we adjust the standard errors of the estimates to take account of this clustering. The clustered standard errors also account for any other nonindependence of children within preschools.

We first use the model specified above to estimate the main effects of the intervention. We further investigate whether these effects are heterogeneous across different groups (child gender, parental education, family income, etc.). To avoid estimating the effects on very small subsamples (and thereby losing explanatory power), we have chosen to include interaction terms between the specific subgroups and the intervention indicator.

To check the robustness of our estimates, we also employ two alternative specifications. The first of these is the more restrictive version of the value-added model where the parameter on the lagged outcome measure is set to one $(\gamma=1)$ and the resulting dependent variable becomes the gain in the outcome measure. In this specification, the gain is then expressed solely as a function of the explanatory variables. The second alternative specification is based on treating the data as 
individual-level panel data (with two observations, from 2011 and 2013, respectively) and specifying a standard panel data model with unobserved individual-specific fixed effects. The intervention effect can then be estimated as the coefficient to a time-varying intervention indicator (see Imbens and Wooldridge, 2007, for further details). In both of these alternative specifications, the standard errors of the estimates are adjusted for clustering at the preschool level.

\section{Main Effects}

We estimate the main effects of the intervention using the value-added specification outlined in the previous section. Our main results are based on the analytic sample consisting of children who participate in the full period from 2011 to 2013. For these children, we have measurements of their socio-emotional skills both before the intervention starts and after it has completed. We use the latter as the dependent variable and the former as an additional explanatory variable, as prescribed for the value-added model. The effect of the intervention is given by the estimated coefficient of the intervention preschool indicator, $\delta$, which basically is the mean difference between children in the intervention and control preschools, net of any other characteristic at the child, family and preschool levels. The effect is measured after the intervention has been completed in 2013 .

The estimation results are reported in Table 4 along with simple mean differences in outcomes between children in the control and intervention groups. The middle panel shows the estimates from a value-added model without any additional explanatory variables (i.e. only the baseline value of the outcome measure has been included along with the intervention indicator) and the bottom panel shows the estimates from a value-added model with a full set of explanatory variables included to control for child, family and preschool characteristics. As expected, the magnitude and significance of the simple mean differences are remarkably similar to the estimates of the value-added model without additional explanatory variables. Moreover, the estimates from the two value-added models 
are also fairly similar in magnitude and significance, which is reassuring since it indicates that the initial randomization has not been undermined. However, the preferred set of estimates is from the model with all explanatory variables included. The coefficient estimates of the explanatory variables, with the exception of the baseline value of the outcome measure and the intervention indicator, are not shown in the table, but are available from the authors upon request.

The overall picture is that the intervention has had positive effects on several SDQ subscales (shown by negatively estimated coefficients for all the outcomes, except the positive coefficient estimate for prosocial behavior, which is in the expected direction). The results show that the intervention significantly improves two of the five SDQ subscales: emotional symptoms and conduct problems. The three remaining subscales are also improved: for peer relationship problems and prosocial behavior at a $10 \%$ significance level, but for hyperactivity the effect is not significant. In addition, it should be noted that both the total SDQ score (representing the total of the first four subscales) and the SDQ impact score are also significantly improved by the intervention, although the latter only at a $10 \%$ significance level. For children in intervention preschools, emotional symptoms have decreased by 0.43 on the SDQ scale and conduct problems have decreased by 0.39 . These decreases are equivalent to 0.22 and 0.33 of a standard deviation for the two outcomes, respectively. Hence, the effect sizes are 0.22 and 0.33 . Effect sizes in the range $0.2-0.4$ are considered moderate by Hattie (2008) and compare favorably to effect sizes on similar outcomes found in experimental evaluations of Head Start and Early Head Start which are in the range 0.110.19 (see Almond and Currie, 2011). They are, however, below the effect sizes found by Raver et al. (2009) who find improvements in teacher-reported behavior problems corresponding to effect sizes in the range $0.53-0.89$, but this is for low-income children. 
Table 4. Main effects, from estimations of value-added models, on the sample of children for the full period, 2011-2013

\begin{tabular}{llllclll}
\hline Emotional & Conduct & Hyper- & Peer & Prosocial & Total & SDQ \\
& symptoms & problems & activity & relation- & sDQ & impact \\
& & & ships & & score & score \\
\hline
\end{tabular}

Simple differences of means ( $t$-tests)

\begin{tabular}{llllllll}
\hline Intervention & $-0.319 * *$ & $-0.424 * * *$ & -0.314 & $-0.246^{* *}$ & $0.550 * * *$ & $-1.303 * * *$ & $-0.186 * * *$ \\
& $(0.140)$ & $(0.125)$ & $(0.209)$ & $(0.115)$ & $(0.157)$ & $(0.451)$ & $(0.057)$ \\
\hline
\end{tabular}

Value-added specification with only lagged outcome measure as explanatory variable

\begin{tabular}{lccccccc}
\hline Intervention & $-0.362 * *$ & $-0.477 * * *$ & -0.379 & -0.253 & $0.465 * *$ & $-1.496^{* *}$ & $-0.180^{* *}$ \\
& $(0.172)$ & $(0.134)$ & $(0.278)$ & $(0.154)$ & $(0.225)$ & $(0.614)$ & $(0.076)$ \\
Lagged & $0.298^{* * *}$ & $0.387 * * *$ & $0.430^{* * *}$ & $0.224 * * *$ & $0.284 * * *$ & $0.418^{* * *}$ & $0.321^{* * *}$ \\
outcome & $(0.046)$ & $(0.043)$ & $(0.038)$ & $(0.049)$ & $(0.040)$ & $(0.036)$ & $(0.047)$ \\
\hline
\end{tabular}

Value-added specification with full set of explanatory variables

\begin{tabular}{lccccccc}
\hline Intervention & $-0.429 * *$ & $-0.385^{* * *}$ & -0.237 & $-0.225 *$ & $0.407 *$ & $-1.326 * *$ & $-0.142 *$ \\
& $(0.204)$ & $(0.133)$ & $(0.279)$ & $(0.133)$ & $(0.223)$ & $(0.634)$ & $(0.075)$ \\
Lagged & $0.289 * * *$ & $0.328 * * *$ & $0.331 * * *$ & $0.204 * * *$ & $0.227 * * *$ & $0.342 * * *$ & $0.295 * * *$ \\
outcome & $(0.050)$ & $(0.040)$ & $(0.043)$ & $(0.050)$ & $(0.044)$ & $(0.035)$ & $(0.055)$
\end{tabular}

Note: $* \mathrm{p}<0.10 ; * * \mathrm{p}<0.05 ; * * * \mathrm{p}<0.01$. Standard errors in parentheses. Standard errors are adjusted for clustering at the preschool level. The full set of explanatory variables consists of: child gender, child ethnicity, mother's education (at least 12 years), father's education (at least 12 years), disposable family income (lowest decile), living with single parent, size of preschool, staff-child ratio, share of staff with education, staff stability, change of principal, and municipality indicators. No. of observations is 686 for the top panel and 597 for the bottom panel. 


\section{Heterogeneous Effects}

Our main results show that several subscales of SDQ are improved by the intervention. However, these main effects reflect the average effects for the intervention group as a whole, and there may be important differences in the effects across various subgroups. In particular, we are interested in investigating whether the intervention is more beneficial for disadvantaged children than for other children. Therefore, we now turn to estimations of specifications where we allow the effects to be heterogeneous across subgroups.

To avoid estimating the effects on very small subsamples (and thereby losing explanatory power), we have chosen to use the value-added specification of the previous section augmented with an interaction term between the specific subgroup and the intervention indicator. In Table 5, we report the results from a number of different specifications with such heterogeneous effects, representing differences across children's gender, parents' education, family income, children's ethnicity, family status, and different preschool characteristics.

Most of these augmented specifications do not show any significantly different effects across subgroups defined on the basis of child and family characteristics. For the subgroups defined on the basis of preschool characteristics, there are more significant differences. There are, however, a number of interesting patterns to be noticed in many of the augmented specifications.

Children's gender. We find that the only effect that is significantly different for boys and girls is regarding conduct problems. The result shows that the intervention improves this subscale for boys, but not for girls. The same pattern emerges from most of the other measures where the intervention gives stronger improvements for boys than for girls, although the effects are not significantly different. The only exception to this pattern is for prosocial behavior. 
Table 5. Heterogeneous effects, from estimations of value-added models, on the sample of children for the full period, 2011-2013

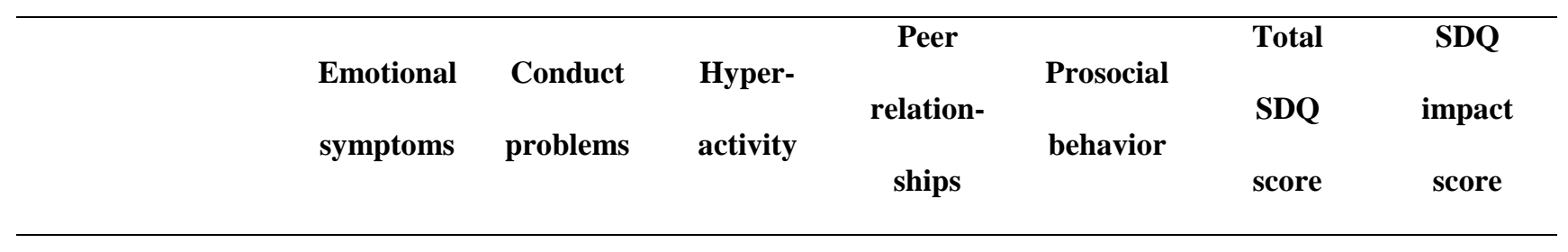

Panel A: Children's gender

\begin{tabular}{lccccccc}
\hline Intervention & -0.387 & -0.128 & -0.073 & -0.002 & $0.469^{*}$ & -0.647 & -0.134 \\
& $(0.254)$ & $(0.163)$ & $(0.284)$ & $(0.208)$ & $(0.254)$ & $(0.767)$ & $(0.087)$ \\
Boy * & -0.077 & $-0.466^{* *}$ & -0.298 & -0.404 & -0.111 & -1.229 & -0.016 \\
intervention & $(0.272)$ & $(0.183)$ & $(0.380)$ & $(0.253)$ & $(0.300)$ & $(0.761)$ & $(0.109)$ \\
\hline
\end{tabular}

Panel B: Mother's education, at least 12 years (vs. less than 12 years)

\begin{tabular}{lccccccc}
\hline Intervention & -0.193 & -0.551 & -0.005 & -0.258 & -0.156 & -0.461 & 0.212 \\
& $(0.411)$ & $(0.400)$ & $(0.603)$ & $(0.306)$ & $(0.498)$ & $(1.317)$ & $(0.120)$ \\
Medu * & -0.276 & 0.193 & -0.271 & $-0.564^{*}$ & 0.656 & -1.008 & $-0.413 * * *$ \\
intervention & $(0.405)$ & $(0.391)$ & $(0.535)$ & $(0.295)$ & $(0.489)$ & $(1.099)$ & $(0.134)$ \\
\hline
\end{tabular}

Panel C: Father's education, at least 12 years (vs. less than 12 years)

\begin{tabular}{lccccccc}
\hline Intervention & -0.189 & -0.220 & 0.161 & 0.270 & 0.000 & 0.015 & -0.100 \\
& $(0.426)$ & $(0.316)$ & $(0.537)$ & $(0.306)$ & $(0.367)$ & $(1.254)$ & $(0.150)$ \\
& -0.296 & -0.202 & -0.489 & $-0.609 *$ & 0.500 & -1.649 & -0.053 \\
Fedu * & & & & & & & \\
intervention & $(0.427)$ & $(0.321)$ & $(0.482)$ & $(0.339)$ & $(0.347)$ & $(1.140)$ & $(0.167)$ \\
\hline
\end{tabular}


Panel D: Low-income family, in lowest decile of income distribution (vs. higher deciles)

\begin{tabular}{lccccccc}
\hline Intervention & $-0.403^{*}$ & $-0.401 * * *$ & -0.173 & $-0.251^{*}$ & $0.421^{*}$ & $-1.291 * *$ & $-0.155^{*}$ \\
& $(0.203)$ & $(0.137)$ & $(0.285)$ & $(0.134)$ & $(0.227)$ & $(0.635)$ & $(0.079)$ \\
Lowinc * & -0.391 & 0.232 & $-0.937 * *$ & 0.382 & -0.211 & -0.500 & 0.197 \\
intervention & $(0.507)$ & $(0.255)$ & $(0.447)$ & $(0.524)$ & $(0.454)$ & $(0.980)$ & $(0.180)$ \\
\hline
\end{tabular}

Panel E: Ethnicity, Danish child (vs. child of non-Danish origin)

\begin{tabular}{lccccccc}
\hline Intervention & 0.056 & 0.060 & 0.470 & -0.148 & -0.125 & 0.355 & 0.129 \\
& $(0.409)$ & $(0.237)$ & $(0.603)$ & $(0.384)$ & $(0.580)$ & $(1.303)$ & $(0.156)$ \\
Danish * & -0.543 & $-0.496^{*}$ & -0.790 & -0.086 & 0.594 & -1.876 & $-0.302^{*}$ \\
intervention & $(0.430)$ & $(0.279)$ & $(0.669)$ & $(0.440)$ & $(0.552)$ & $(1.458)$ & $(0.172)$ \\
\hline
\end{tabular}

Panel F: Family status, single parent (vs. both parents)

\begin{tabular}{lccccccc}
\hline Intervention & $-0.485^{* *}$ & $-0.362^{* *}$ & -0.346 & $-0.320 * *$ & $0.485^{* *}$ & $-1.576^{* *}$ & $-0.162^{* *}$ \\
& $(0.199)$ & $(0.135)$ & $(0.279)$ & $(0.139)$ & $(0.227)$ & $(0.628)$ & $(0.079)$ \\
Single par. $*$ & 0.507 & -0.204 & 0.974 & $0.865^{* *}$ & -0.719 & 2.245 & 0.185 \\
intervention & $(0.416)$ & $(0.632)$ & $(0.792)$ & $(0.423)$ & $(0.460)$ & $(1.818)$ & $(0.228)$ \\
\hline
\end{tabular}

Panel G: Preschool's share of socially disadvantaged children, high share (vs. lower share)

\begin{tabular}{lccccccc}
\hline Intervention & $-0.538^{* *}$ & $-0.372 * *$ & -0.248 & $-0.271^{*}$ & $0.503 * *$ & $-1.466^{* *}$ & $-0.170^{* *}$ \\
& $(0.204)$ & $(0.142)$ & $(0.287)$ & $(0.139)$ & $(0.217)$ & $(0.653)$ & $(0.075)$ \\
Soc. disadv. * & $1.365^{* * *}$ & -0.156 & 0.139 & 0.595 & $-1.195^{* *}$ & 1.825 & $0.377^{*}$ \\
intervention & $(0.441)$ & $(0.266)$ & $(0.590)$ & $(0.366)$ & $(0.572)$ & $(1.158)$ & $(0.201)$ \\
\hline
\end{tabular}


Panel H: Preschool's stability of staff, high stability (vs. lower stability)

\begin{tabular}{lccccccc}
\hline Intervention & -0.183 & -0.055 & 0.210 & 0.065 & 0.214 & 0.009 & 0.060 \\
& $(0.281)$ & $(0.177)$ & $(0.306)$ & $(0.185)$ & $(0.331)$ & $(0.646)$ & $(0.084)$ \\
Stability * & -0.291 & $-0.390^{* *}$ & $-0.530^{*}$ & -0.343 & 0.229 & $-1.580^{* *}$ & $-0.240 * *$ \\
intervention & $(0.289)$ & $(0.187)$ & $(0.309)$ & $(0.208)$ & $(0.315)$ & $(0.673)$ & $(0.108)$ \\
\hline
\end{tabular}

Note: $* \mathrm{p}<0.10 ; * * \mathrm{p}<0.05 ; * * * \mathrm{p}<0.01$. Standard errors in parentheses. Standard errors are adjusted for clustering at the preschool level. All specifications include: lagged outcome measure, child gender, child ethnicity, mother's education (at least 12 years), father's education (at least 12 years), disposable family income (lowest decile), living with single parent, size of preschool, staff-child ratio, share of staff with education, staff stability, change of principal, and municipality indicators. No. of observations is 597, except for the SDQ impact score where it is 567.

Parents' education. We distinguish between mothers and fathers with less than 12 years of education (low educated) and those with at least 12 years of education (highly educated). The only effect that is significantly different is for the SDQ impact score, where children of highly-educated mothers have a much stronger improvement. For peer relationships, both mother's and father's education leads to stronger improvement, at a $10 \%$ significance level. Again, we observe a pattern where the effects of the intervention are stronger for children of highly-educated parents, whereas there is basically no effect on any measure for children of low-educated parents. In particular, it is observed that children of low-educated fathers do not gain from the intervention.

Family income. Children from families with a very low income (below the first decile of the income distribution) as a general picture have the same effects as children from better-off families. The exception to this is for hyperactivity, where children from low-income families have a significantly better improvement due to the intervention. 
Ethnicity. Again, we observe the same pattern as for parents' education with the intervention having basically no effect on any measure for children of non-Danish origin. However, it should be noted that the group of children of non-Danish origin is quite diverse and consists of children from very different backgrounds, e.g. non-Western immigrants but also children from other Scandinavian countries. The improvements only occur for Danish children, but they are in most cases not significant for this subgroup. Thus, in this sample of children, ethnicity does not seem to matter much for the effect of the intervention.

Family status. Regarding family status we have employed a specification where we use an indicator for whether the child lives with only a single parent or with two parents (regardless of whether they are married or cohabiting - this distinction being relatively unimportant in a Danish context). The results clearly show that the intervention leads to significant improvements in all measures (except hyperactivity) for children living with two parents. There is a significantly different effect for peer relationships such that children living with a single parent see no improvement from the intervention on this subscale. Looking closer at the resulting effects for children of single parents, it appears that the intervention has basically no effects for these children (except regarding conduct problems), and that for all measures (with the exception of conduct problems) they actually worsen the SDQ scores. However, these effects are relatively imprecisely estimated and hence not significant.

Share of socially disadvantaged children. We have divided the preschools into two groups: those with a high share of socially disadvantaged children $(>40 \%)$ and those with a lower share. $12 \%$ of the children in the analyzed sample attend the former group of preschools. The results clearly show that the intervention leads to significant improvements in all measures (except hyperactivity not being significant) for children attending preschools with a low share of socially disadvantaged children. There are significantly different effects across the two types of preschools for two SDQ 
subscales, namely emotional symptoms and prosocial behavior. In both cases, the effects of the intervention are strongly reversed such that children in preschools with a high share of socially disadvantaged children are worse off (as opposed to the significant improvement shown by the main effect).

Stability of staff. We have again divided the preschools into two groups: those with a high turnover rate of the staff (more than $30 \%$ annual turnover) and those with a lower turnover rate (i.e. high stability). ${ }^{16} 12 \%$ of children in the analyzed sample attend the former group of preschools. The results show that the intervention is much more effective in high-stability preschools where it leads to improvements in all measures for children attending these preschools (with significant improvements for conduct problems, the total SDQ score, and the SDQ impact score). For children in preschools with a high turnover rate among the staff, the intervention fails to create improvements in any of the measures. This result is not surprising as the intervention is based on training some teachers in each preschool, and the newly trained teachers thereafter share their knowledge and ideas with the rest of the teachers. Together they adapt and implement the new knowledge in the preschool. A highly changing pool of teachers from year to year could make it difficult to absorb the new changes in the preschool and to make them a common foundation for the pedagogical work.

To summarize, the general picture emerging from the analysis of heterogeneous effects for child and family characteristics (Panels A-F) shows that generally the intervention has not been able to produce larger improvements for socially disadvantaged children than for other children. In a

\footnotetext{
${ }^{16}$ The selection of the threshold of $30 \%$ turnover is based upon an investigation of different threshold values and resulting sizes of the subgroups. Since most preschools experience some turnover of their staff during a year (and one person may constitute 5-10\% of the staff), very low threshold values have no explanatory power. We also estimated a version of the model with a continuous measure of turnover in the interaction term and that specification gave qualitatively similar results.
} 
number of cases we even find results indicating that the intervention has no effects for socially disadvantaged children. The only exception to this general picture is that the intervention has significantly reduced hyperactivity among children from low-income families, despite the fact that the intervention did not have a significant main effect on this subscale. We find more heterogeneous effects for the subgroups defined on the basis of preschool characteristics (Panels G-H) than for those defined on the basis of child and family characteristics (Panels A-F). The results show that the intervention does not succeed in creating improved child outcomes for children attending preschools characterized by either a high share of socially disadvantaged children or a high turnover rate among the staff. In general, the investigation of heterogeneous effects both across child and family characteristics and across preschool characteristics shows that the intervention is actually less beneficial for socially disadvantaged children than for other children, contrary to the stated intentions.

\section{Sensitivity Analyses}

\subsection{Alternative Specifications}

This section reports results from various sensitivity analyses where we have employed a number of different specifications to investigate the robustness of our main results. Our main results come from a value-added model that includes a large set of explanatory variables to control for child, family, and preschool characteristics. To check the robustness of our estimates, we employ two alternative specifications: a restricted value-added model and a panel data model with individualspecific fixed effects (see also the description in Section 6). ${ }^{17}$

\footnotetext{
${ }^{17}$ Detailed results from these alternative specifications are not reported here, but are available on request.
} 
The restricted value-added specification models the changes in the outcome measures as a function of the explanatory variables, i.e. it sets the parameter on the lagged outcome measure equal to one. Since the results reported in Section 7 show that the estimates of these parameters lie around 0.3, we would prefer the main effects from the unrestricted value-added model as they are better supported by the data. However, the main effects estimated from the restricted value-added model are qualitatively similar to those obtained from the unrestricted model, although they in most cases are stronger in the sense that their magnitude are larger and they are more significant.

As another alternative specification, we employ a panel data model with individual-specific fixed effects. This allows us to estimate the intervention effects controlling for all unobserved timeconstant characteristics, but the presence of the fixed effects does not allow us to include timeconstant explanatory variables. ${ }^{18}$ In general, the main effects estimated by the panel data approach are very similar to those obtained from the restricted value-added model, which means that they are stronger than (larger magnitude and higher significance) but qualitatively similar to those obtained from the unrestricted value-added model. We can thus conclude that the main effects are fairly robust against changes in the specification of the model, and that the effects reported in Section 7 are probably rather conservative estimates of the intervention effects. When using the alternative specifications to investigate heterogeneous effects, the picture becomes more blurred. For the subgroups defined on the basis of child and family characteristics, we again find quite few heterogeneous effects that are significantly different across subgroups, but they are much more volatile than the main effects. The most obvious reason for this is presumably the very small sample sizes of the subgroups. Thus, the specific heterogeneous effects should be interpreted with some care, but the overall picture is confirmed by the sensitivity analyses (and for the panel data

\footnotetext{
${ }^{18}$ The panel data model also includes time trends which capture the autonomous improvement over time in SDQ scores.
} 
specification it is even stronger): the intervention has not been able to produce larger improvements for socially disadvantaged children than for other children, and in some cases even less improvements. The heterogeneous effects across preschool characteristics are confirmed by the sensitivity analyses.

Including the control variables also provides us with information about which background characteristics determine the socio-emotional skills of the children (as measured by SDQ). As several previous studies, we find that girls generally have better outcomes on all five SDQ dimensions and that parents' education is a strong predictor for child outcomes across all five SDQ dimensions, with better outcomes measured for children whose parents have more education. Ethnicity affects some of the outcomes, but not in a consistent way.

\subsection{Midway Analysis}

Another way to investigate the robustness of the effects is to perform a midway analysis of the effects of the intervention. Instead of analyzing the effects after the full period of the intervention, it is possible to analyze the effects half way through the intervention, i.e. after the first year of the intervention, since all outcomes have also been measured in March 2012. Such a midway analysis can be performed on two different samples, either on the same sample as above, i.e. the children enrolled for the full period of 2011-2013, or on an enlarged sample consisting of all children enrolled in 2011 and 2012. About half of the latter will have left the preschools in 2013, because they have become old enough to be admitted to grade 0 of primary school. Basing the analysis on this latter sample will thus give us more precise estimates due to the larger number of observations. We can also perform a separate analysis on the children that have joined the preschools in 2012 and still are enrolled in 2013. 
Results on the first subperiod (2011-2012) do not show any significant effects of the intervention, despite more precise estimates. This holds for the five SDQ subscales, the total score, and the impact score. There are a few significantly different effects across subgroups. To summarize, the effects are smaller and in most cases not significant, but the overall picture is confirmed.

Results on the second subperiod (2012-2013) also do not show any significant effects of the intervention, again despite more precise estimates. There are no systematic patterns in the heterogeneous effects. One possible explanation of the results for the second subperiod is that the children included in this analysis are quite young children, since they have just entered the preschools between the start in 2011 and the midway data wave in 2012. If the intervention has stronger effects on older children than on younger children, this could explain these results. However, the age aspect will not be investigated further here as it falls outside the scope of our analysis.

The conclusion of this sensitivity analysis is that the effects cannot be found in any of the two subperiods, but that the full period is required to obtain significant effects of the intervention. We are not surprised about this result as it probably takes some time for the new pedagogical routines to be implemented and to have a direct effect on the children.

\section{Discussion and Conclusion}

International studies have shown that early interventions can have positive effects in the sense that (especially) socially disadvantaged children are more likely to prosper, in both the short and the long run, if they receive social and intellectual stimulation from an early age. However, the studies do not tell us about benefits for children in a system of universal daycare, where all children participate regardless of their socio-economic background, as is the case in Denmark with a participation rate of 97\% among children aged 3-5 in 2010. 
We evaluate an intervention (the VIDA intervention) that is designed to investigate whether education, training and knowledge sharing of preschool teachers (and managers) affect child socioemotional outcomes. If there are effects, do these vary among different groups of children or across different preschool characteristics? The intervention was evaluated using a cluster-RCT design with random assignment at the preschool level. The intervention was implemented in 29 preschools (and compared with 29 control preschools) in three Danish municipalities.

The intervention distinguishes itself from other interventions found in existing international studies in two ways. Firstly, it focuses on professional development of preschool teachers to implement an intervention aimed at enhancing child socio-emotional development via an inclusive pedagogy, i.e. it is founded theoretically in the bioecological perspective. Secondly, the intervention is designed for implementation in universal public daycare where almost all children attend. The preschool teachers are trained to implement a specific learning and developmental program and thereby to change the entire system (interactions, inclusion, and teacher qualification). The professional development focused on teaching the participants to develop activities and renew practices that could improve the individual child's development through responsive supportive interaction and through inclusive learning environments. The preschool teachers trained this approach through ongoing educational and training sessions where they learned to implement the program.

Our focus is on socio-emotional competences, i.e. child behavior and well-being, as measured by the five subscales of the SDQ scale (Goodman, 1997). Effects are analyzed by comparing baseline measures of SDQ to measures collected at the end of the intervention. The results show that the professional development of preschool teachers provided by the intervention has positive effects on development and behavior among children aged 3-5. The intervention significantly improves children's emotional development and causes a reduction in emotional and behavioral problems with an effect size of 0.22-0.33. However, the results also show that the intervention is not 
successful in producing larger improvements for socially disadvantaged children than for other children. Finally, the results show that certain characteristics of the preschools may act as barriers to a successful outcome of the intervention, as no improvements are found for children attending preschools with a high share of socially disadvantaged children or a high turnover rate among the staff.

Comparing the findings of this study with existing international studies, it is noticeable that we do not find stronger effects on socially disadvantaged children than on their more privileged peers. Previous studies (e.g. of the effects of the Perry Pre-School Project) have often found very strong effects of interventions on socially disadvantaged children, but these interventions have typically been targeted towards this group and the control group has consisted of children who have not attended any daycare. In our case, at least two aspects are probably explaining why we obtain a different result. Firstly, the intervention has been implemented in a universal daycare system where socially disadvantaged children are already attending preschools, i.e. they are also in the control group and thereby participating in activities rooted in the Act on Educational Curricula. Secondly, the intervention is based on professional development of the preschool teachers and as such it is much less targeted towards socially disadvantaged children. In line with this, we also find that the success of the intervention depends critically on the characteristics of the preschools, both in terms of the composition of the child group and in terms of structural quality measured by the turnover rate of the staff. Hence, basing an intervention on professional development of the preschool teachers may be effective in many cases, but it contains risky components since a high turnover among the preschool teachers may erode the basis of the intervention. This is consistent with other recent research on Danish register data indicating that a high structural quality of preschools (measured e.g. by staff-child ratios and educational level of the staff) can have positive long-term effects (see Bauchmüller et al., 2014). 
A possible limitation of this study is that some of the participating municipalities have had other interventions at the same time as the VIDA intervention. One municipality has implemented a socalled 'vision project' for all preschools in the municipality. This should affect intervention and control preschools in the same way, but potentially leads to a (downward) bias in the effects of the current intervention. Another municipality initiated an 'inclusion project' in 2013 by offering posteducation training of preschool teachers. We do not believe that this project interferes with the results from the current intervention as the project started almost at the same time as our final data collection. To control for potential municipality differences, all reported estimations included municipality fixed effects. Another limitation of the current study is the focus on children's socioemotional outcomes as measured by SDQ scores. SDQ is based on teacher ratings which potentially are subjective. Thus, in terms of generalizability of the results, it would also be nice to have objective data on child outcomes from cognitive tests.

In summary, the current study has contributed to fill some of the knowledge gap about how professional development of preschool teachers may affect child socio-emotional outcomes. We have provided evidence showing that it is possible to improve child outcomes through an intervention focused on preschool teachers, but that it is not effective as a special way to target socially disadvantaged children, at least not in a universal daycare system. The evidence also points to some challenges in implementing organizational changes and learning approaches to professional development, as it clearly requires some stability of the staff. Future implementations need to carefully consider the composition of the child group, as preschools with a high share of socially disadvantaged children do not seem to benefit, and it may also be important to combine the professional development with additional measures for increasing the stability of the staff. 


\section{References}

Almond, Douglas, and Janet Currie (2011). Human capital development before age five. In Handbook of Labor Economics, Volume 4b, Ch. 15, ed. O. Ashenfelter and D. Card, 1315-1486, Amsterdam: Elsevier.

Baker, Michael, Jonathan Gruber, and Kevin Milligan (2008). Universal child care, maternal labor supply, and family well-being. Journal of Political Economy 116, 709-45.

Barnett, W. Steven and Leonard N. Masse (2007). Comparative Benefit-Cost Analysis of the Abecedarian Program and its Policy Implications. Economics of Education Review 26, 113-125.

Barnett, W. Steven, and Clive R. Belfield (2006). Early childhood development and social mobility. Future of Children 16, 73-98.

Bauchmüller, Robert, Mette Gørtz, and Astrid Würtz Rasmussen (2014). Long-Run Benefits from Universal High-Quality Preschooling. Early Childhood Research Quarterly 29, 457-470.

Blau, David, and Janet Currie (2006). Pre-school, day care and after-school care: Who's minding the kids? In Handbook of the Economics of Education, Volume 2, Ch. 20, ed. E. Hanushek and F. Welch, 1163-1278, Amsterdam: Elsevier.

Bronfenbrenner, Urie (1979). The ecology of human development. Cambridge: Harvard University Press.

Bronfenbrenner, Urie and Pamela A. Morris (2006). The bioecological model of human development. In Handbook of child psychology: Theoretical models of human development, Volume. 1, ed. W. Damon and R. M. Lerner, 793-828, New York: Wiley.

Brown, John S., and Paul Duguid (1991). Organizational Learning and Communities-of-Practice: Towards a unified view of working, learning and innovation. Organization Science 2, 40-57. 
Burger, Kaspar (2010). How does early childhood care and education affect cognitive development? An international review of the effects of early interventions for children from different social backgrounds. Early Childhood Research Quarterly 25, 140-165.

Cameron, Claire E. (2012). A transactional Model of Effective Teaching and Learning in the Early Childhood Classroom. In Handbook of Early Childhood Education. ed. R. C. Pianta, 278-296, New York: Guildford Press.

Chetty, Raj, John N. Friedman, Nathaniel Hilger, Emmanuel Saez, Diane W. Schanzenbach, and Danny Yagan (2011). How does your kindergarten classroom affect your earnings? Evidence from project STAR. The Quarterly Journal of Economics 126, 1593-1660.

Claessens, Amy, Mimi Engel, and F. Chris Curran (2014). Academic content, student learning, and the persistence of preschool effects. American Educational Research Journal 51, 403-434.

Cunha, Flavio, James J. Heckman, Lance Lochner, and Dimitriy V. Masterov (2006). Intepreting the Evidence on Life Cycle Skill Formation. In Handbook of the Economics of Education, Volume 1, Ch. 12, ed. E. Hanushek and F. Welsh, 697-812, Amsterdam: Elsevier.

Datta Gupta, Nabanita, and Marianne Simonsen (2010). Non-cognitive child outcomes and universal high quality child care. Journal of Public Economics 94, 30-43.

Duncan, Greg J., and Aaron J. Sojourner (2013). Can intensive early childhood intervention programs eliminate income-based cognitive and achievement gaps? The Journal of Human Resources 48, 945-968.

Ellström, Per-Erik (2010). Practice-based innovation: a learning perspective. Journal of Workplace Learning 22, 27-40. 
Gheradi, Silvia (2011). Organizational Learning: The Sociology of Practice. In The Blackwell Handbook of Organizational Learning and Knowledge Management, ed. M. Easterby-Smith and M. A. Lyles, 43-65, Oxford: Blackwell Publishing.

Goodman, Robert (1997). The strengths and difficulties questionnaire: a research note. Journal of Child Psychology and Psychiatry 38, 581-586.

Goodman, Robert (1999). The extended version of the strengths and difficulties questionnaire as a guide to child psychiatric caseness and consequent burden. Journal of Child Psychology and Psychiatry 40, 791-799.

Goodman, Anna, and Goodman, Robert (2009). Strengths and difficulties questionnaire as a dimensional measure of child mental health. Journal of the American Academy of Child and Adolescent Psychiatry 48, 400-403.

Hamre, Bridget, Jason T. Downer, Faiza M. Jamil, and Robert C. Pianta (2012). Enhanching Teachers' Intentional Use of Effective Interactions with Children. In Handbook of Early Childhood Education. ed. R. C. Pianta, 507- 532, New York: Guildford Press.

Hattie, John A. C. (2008). Visible Learning: A synthesis of over 800 meta-analyses relating to achievement. London: Routledge.

Havnes, Tarjei and Magne Mogstad (2011). No Child Left Behind: Subsidized Child Care and Children's Long-Run Outcomes. American Economic Journal: Economic Policy 3, 97-129.

Heckman, James J. (2006). Skill Formation and the Economics of Investing in Disadvantaged Children. Science 312, 1900-1902.

Heckman, James J. (2008). Schools, Skills and Synapses. Economic Inquiry 46, 289-324. 
Heckman, James J., Seong Hyeok Moon, Rodrigo Pinto, Peter A. Savelyev, and Adam Yavitz (2010). The rate of return to the HighScope Perry Preschool Program. Journal of Public Economics 94, 114-128.

Heckman, James J., and Tim Kautz (2012). Hard evidence on soft skills. IZA Discussion Paper 6580, Bonn.

Imbens, Guido, and Jeffrey Wooldridge (2007). What's new in econometrics? Lecture notes (lecture 10), NBER Summer Institute (available at www.nber.org).

Jensen, Bente, Anders Holm, Camilla Wang, Dorte Kousholt, Ib Ravn, Michael S. Larsen, Ove S. Rasmussen, Peter Berliner, Thomas Y. Andersen, and Ulrik Brandi (2011). Vidensbaseret indsats over for udsatte børn i dagtilbud - modelprogram, Statusrapport 1. VIDA-forskningsserien 2011:1, Aarhus Universitet.

Jensen, Bente, Anders Holm, and Sven Bremberg (2013). Effectiveness of a Danish early year preschool program: A randomized trial. International Journal of Educational Research 62, 115128.

Jensen, Morten B., Björn Johnson, Edward Lorenz, and Bengt Å. Lundvall (2007). Forms of knowledge and modes of innovation. Research Policy 36, 680-693.

Lipsey, Mark W., Kelly Puzio, Cathy Yun, Michael A. Hebert, Kasia Steinka-Fry, Mikel W. Cole, Megan Roberts, Karen S. Anthony, and Matthew D. Busick (2012). Translating the statistical representation of the effects of education interventions into more readily interpretable forms. NCSER 2013-3000, U.S. Department of Education.

Mashburn, Andrew J., Robert C. Pianta, Bridget K. Hamre, Jason T. Downer. Oscar A. Barbarin, Donna Bryant, Margaret Burchinal, Diane M. Early, and Carollee Howes (2008). Measures of 
classroom quality in prekindergarten and children's development of academic, language, and social skills. Child Development 79, 732-749.

Morris, Richard J. (1985). Behavior modification with exceptional children. Principles and practices. Glenview: Scott, Foresman.

Pianta, Robert C., W. Steven Barnett, Margaret Burchinal, and Kathy R. Thornburg (2009). The effects of preschool education: what we know, how public policy is or is not aligned with the evidence base, and what we need to know. Psychological Science in the Public Interest 10, 49-88.

Pine, Fred (1985). Developmental theory and clinical process. New Haven: Yale University Press.

Raver, C. Cybele, Stephanie M. Jones, Christine Li-Grining, Fuhua Zhai, Molly W. Metzger, and Bonnie Solomon (2009). Targeting children's behavior problems in preschool classrooms: A cluster-randomized controlled trial. Journal of Consulting and Clinical Psychology 77, 302-316.

Rutter, Michael (2006). Genes and Behavior: Nature-Nurture Interplay explained. Malden: Blackwell Publishing.

Schweinhart, Lawrence J., Jeanne Montie, Zongping Xiang, W. Steven Barnett, Clive R.Belfield, and Milagros Nores (2005). Lifetime Effects: The High/Scope Perry Preschool Study Through Age 40.Ypsilanti: High/Scope Press.

Statistics Denmark. 2015, www.statistikbanken.dk, Tables PAS11 and BEF5 (accessed February 3, 2015).

Stern, Daniel N. (1985). The interpersonal world of the infant. New York: Basic Books. 
Sundbo, Jon (2003). Innovation and Strategic Reflexivity: An Evolutionary Approach Applied to Services. In The International Handbook of Innovation, ed. L. V. Shavinina, 97-114. New York: Pergamon Press.

Temple, Judy A., and Arthur J. Reynolds (2007). Benefits and costs of investment in preschool education: Evidence from the Child-Parent Centers and related programs. Economics of Education Review 26, 126-144.

Todd, Petra E., and Kenneth I. Wolpin (2007). The production of cognitive achievement in children: Home, school, and racial test score gaps. Journal of Human Capital 1, 91-136.

Vygotsky, Lev (1978). Mind in Society. Cambridge: Harvard University Press. 